\title{
The use of systematic reviews to justify phase III ophthalmology trials: an analysis
}

\author{
Trevor Torgerson $\mathbb{1}^{1} \cdot$ Sheridan Evans ${ }^{1} \cdot$ Bradley S. Johnson $\mathbb{1}^{1} \cdot$ Matt Vassar $^{1}$
}

Received: 10 July 2019 / Revised: 23 October 2019 / Accepted: 5 January 2020 / Published online: 21 January 2020

(c) The Author(s), under exclusive licence to The Royal College of Ophthalmologists 2020

\begin{abstract}
Background/objective Given the drastic increase in publication output in recent years, minimizing research waste should be a top priority. There are established areas of concern regarding research waste within ophthalmology along with a lack of systematic review usage to inform trial design in other areas of medicine. Given these concerns, the aim of this study is to evaluate the use of systematic reviews as justification for conducting randomized controlled trials (RCT) in top ophthalmology and optometry journals.

Methods We searched PubMed on December 5, 2018 for RCTs published in one of the top five Google Scholar h-5 index journals within Ophthalmology and Optometry. We used a pilot-tested Google Form and searched each RCT for systematic reviews. Each systematic review was then given the designation of "verbatim", "inferred", or "not used as justification for conducting the RCT" based on the context the systematic review was used.

Results Our analysis yielded 152 included phase III RCTs. We found 22.4\% (34 of 152) of phase III ophthalmology clinical trials cited a systematic review as justification for conducting the trial. A total of 102 systematic reviews were cited in the 152 RCTs. Fifty-seven of the one hundred fifty-two (37.5\%) RCTs cited a systematic review somewhere in the manuscript. Conclusion Less than one-quarter of phase III RCTs cited systematic reviews as justification for conducting the RCT. We believe placing a higher priority on justifying RCTs with systematic reviews would go a long way to minimizing research waste within ophthalmology.
\end{abstract}

\section{Introduction}

The annual number of medical research citations has more than doubled since 2000 , reaching nearly one million citations in 2017 [1]. This increase is to be expected considering that global investment in biomedical research reached US \$240 billion in 2010 [2]. However, the United States over recent years has seen stagnation in biomedical research funding, specifically from the NIH [3, 4]. Given the trajectory of biomedical research funding and the drastic increase in publication output, minimizing research waste should be a top priority.

Research waste has become far too common, as one study suggests as much as $85 \%$ of research could be

Trevor Torgerson

trevor.torgerson@okstate.edu

1 Office of Medical Student Research, Oklahoma State University Center for Health Sciences, Tulsa, OK, USA considered wasteful [5]. Chalmers and Glasziou define research waste in four general categories [5-7]; research that has little clinical significance, research that lacks a quality design, research that never makes it to publication, and research signified by biased and unusable reports.

With regard to this study, research waste is defined as lacking quality design by conducting clinical research where evidence for a hypothesis already exists. For example, one study found that over $50 \%$ of research studies analyzed did not consult a systematic review before designing the study [5]. Systematic reviews are the gold standard in evidence-based medicine. They aim to compile, summarize, and critically analyze the current literature on a specific topic to enable physicians and researchers to make informed decisions [8]. The American Academy of Ophthalmology states that guidelines underpinned by systematic reviews are considered "level 1 evidence" [9]. In this way, systematic reviews are used as a basis to shape clinical care. For example, antioxidant vitamin and mineral supplements were being marketed for improvements in age-related macular degeneration. However, a recent systematic 
review concluded that there was no such improvement with these vitamins [10].

Systematic reviews should not only be consulted at the time of trial design, but also when presenting individual randomized controlled trial (RCT) data in the context of the current literature. However, numerous studies have shown that many researchers are not consulting systematic reviews at all [8]. For example, when Rosenthal et al. analyzed systematic reviews in surgical trials, they found $65 \%$ cited a systematic review somewhere in the manuscript, $16 \%$ of which are in the introduction, but none of these studies specifically used a systematic review as justification for conducting the trial [11].

Ophthalmology and optometry research is not immune to research waste. A major influencer of research waste within ophthalmology is a lack of standardization in RCT primary outcomes. For example, one study found extensive diversity within primary outcomes in registered uveitis trials [12]. However, Core Outcome Measures in Effectiveness Trials has been a leader in standardizing outcome measures in Ophthalmology, particularly in glaucoma trials [13]. Given the areas of concern regarding research waste within ophthalmology and the lack of systematic review usage to inform trial design in other areas of medicine, more studies are needed to uncover how trial design may influence research waste within ophthalmology and optometry. The aim of this study is to evaluate the use of systematic reviews to justify conducting a RCTs in top ophthalmology and optometry journals.

\section{Methods}

One of us (TT) searched PubMed on December 5, 2018 for RCTs published in one of the top five Google Scholar h-5 index journals within Ophthalmology and Optometry. These journals included Ophthalmology, Investigative Ophthalmology \& Visual Science, American Journal of Ophthalmology, JAMA Ophthalmology, and Retina. We used the Cochrane highly sensitive search strategy for RCTs“"((()((()([Publication Type]) OR controlled clinical trial[Publication Type]) OR randomized [tiab]) OR placebo [tiab]) OR drug therapy [sh]) OR randomly [tiab]) OR trial [tiab]) OR groups [tiab]) AND (“2016/01/01"[PDat]: “2018/12/05”[PDat]) AND Humans[Mesh])) AND ((()((“Retina (Philadelphia, Pa.)”[Journal]) OR “American journal of ophthalmology"[Journal]) OR "Ophthalmology"[Journal]) OR "Investigative ophthalmology \& visual science"[Journal]) OR “JAMA ophthalmology"[Journal]) AND ("2016/01/01”[PDat]: “2018/12/05”[PDat]) AND Humans[Mesh])" We used Rayyan (https://rayyan.qcri.org) to screen and excluded any trials that were not Phase III RCTs.
We used a pilot-tested Google Form for all extractions. We searched each RCT for the number of systematic review cited in the introduction, methods, and discussion. Systematic reviews and meta-analyses were considered synonymous for the purposes of this study. Each systematic review was then given the designation of "used verbatim as justification for conducting RCT," "inferred use as justification for conducting RCT," or "not used as justification for conducting RCT" based on the context the systematic review was used. Rationales for each designation were recorded for future resolution. We also extracted trial characteristics that consisted of funding source, type of intervention, number of trial centers, location of study, type of trial, and efficacy of results. Finally, of the RCTs that cited a systematic review as justification for conducting the RCT (verbatim or inferred), we extracted the total number of included studies and patient population for each systematic review. Two of us (BJ, SE) completed the extraction blind and duplicated. All discrepancies were resolved unanimously. This study does not meet the regulatory definition of human subjects research and, thus, is excluded from IRB oversight.

The data were recorded and sorted in an Excel document by journal, section of paper, verbatim, inferred, not used as justification, and trial characteristics. We ran a logistic regression relating trial characteristics to whether a systematic review was used as justification for conducting the trial (verbatim and inferred were included as "justified") using Stata Version 15.1 (StataCorp).

\section{Results}

The search string retrieved 1667 returns, of which, 1515 were excluded as they were inaccessible or were not phase III RCTs. Three hundred and fifty-nine were accessible and screened for inclusion. One hundred fifty-two phase III RCTs were included for analysis. The most common journals in the sample were Ophthalmology (60 of 152) and American Journal of Ophthalmology (46 of 152). The majority of trials was from a single country (88 of 152) and were multicenter trials (87 of 152). Drug was the most common intervention type (73 of 152). A complete depiction of trial characteristics is reported in Table 1.

After analysis, we found $22.4 \%$ (34 of 152) of phase III ophthalmology clinical trials cited a systematic review as justification for conducting the trial (Table 2). Fourteen trials cited at least one systematic review as verbatim justification for conducting the trial and 28 trials cited at least one systematic review as inferred justification for conducting the RCT. Some trials were given the verbatim or inferred distinction in the introduction, then the opposite in the discussion and were therefore counted as one for each. Characteristics of the systematic reviews used to justify (verbatim or inferred) RCTs are included in Table 3 . 
Table 1 Logistic regression analysis of trial characteristics and systematic review citations as justification of trial conduction (a).

\begin{tabular}{|c|c|c|c|}
\hline \multirow[b]{2}{*}{ Covariables } & \multirow[b]{2}{*}{$\begin{array}{l}\text { No. }(\%) \text { of Articles } \\
(N=152)\end{array}$} & \multicolumn{2}{|c|}{ Odds Ratio $(95 \% \mathrm{Cl})$} \\
\hline & & Unadjusted & Adjusted \\
\hline \multicolumn{4}{|l|}{ Journals } \\
\hline Ophthalmology & $60(39.5)$ & 1 [Reference] & 1 [Reference] \\
\hline American Journal of Ophthalmology & $46(30.3)$ & $1.41(0.57-3.52)$ & $1.99(0.73-5.42)$ \\
\hline $\begin{array}{l}\text { Investigative Ophthalmology \& } \\
\text { Visual Science }\end{array}$ & $19(12.5)$ & $1.07(0.30-3.80)$ & $1.06(0.27-4.17)$ \\
\hline JAMA Ophthalmology & $15(9.9)$ & $1.45(0.39-5.38)$ & $1.61(0.40-6.44)$ \\
\hline Retina & $12(7.9)$ & $1.33(0.31-5.69)$ & $2.08(0.43-10.13)$ \\
\hline \multicolumn{4}{|l|}{ Funding source } \\
\hline Non Industry & $77(50.1)$ & 1 [Reference] & 1 [Reference] \\
\hline Industry & $75(49.9)$ & $1.75(0.81-3.77)$ & $1.70(0.69-4.22)$ \\
\hline \multicolumn{4}{|l|}{ Intervention } \\
\hline Procedure & $39(25.7)$ & 1 [Reference] & 1 [Reference] \\
\hline Drug & $73(48.0)$ & $0.86(0.34-2.20)$ & $0.55(0.19-1.59)$ \\
\hline Other & $40(26.3)$ & $1.26(0.46-3.50)$ & $1.37(0.45-4.16)$ \\
\hline \multicolumn{4}{|l|}{ Type of trial center } \\
\hline Single Center & 48 (31.6) & 1 [Reference] & 1 [Reference] \\
\hline Multicenter & $87(57.2)$ & $1.29(0.55-3.00)$ & $1.35(0.44-4.16)$ \\
\hline Not Reported & $17(11.1)$ & $0.81(0.20-3.40)$ & $4.53(3.22-63.73)$ \\
\hline \multicolumn{4}{|l|}{ Location of trial center } \\
\hline Single Country & $88(57.9)$ & 1 [Reference] & 1 [Reference] \\
\hline Multination & $32(21.1)$ & $1.78(0.74-4.31)$ & $1.98(0.64-6.07)$ \\
\hline Not Reported & $32(21.1)$ & $0.49(0.15-1.55)$ & $0.17(0.02-1.58)$ \\
\hline Sample size* mean (range) & $254.6(8-3482)$ & $1.00(0.99-1.00)$ & $1.00(0.99-1.00)$ \\
\hline
\end{tabular}

Logistic regression adjusted for journals, funding source, intervention, and sample size

(*) - Based on a continuous scale
Thirty-four RCTs cited systematic reviews that were not used as justification for conducting the trial.

A total of 102 systematic reviews were cited in the 152 RCTs. Fifty-seven of the one hundred fifty-two (37.5\%) included RCTs cited at least one systematic review somewhere in the manuscript. The logistic regression did not yield any statistically significant results.

\section{Discussion}

Less than one-quarter of phase III RCTs cited systematic reviews as justification for conducting the RCT. We also found only $37 \%$ of phase III RCTs cited a systematic review in the manuscript. This finding aligns with a similar study in anesthesiology which reported less than one-fifth of analyzed studies cited a systematic review as justification for the RCT and only $44 \%$ referenced at least one systematic review in the manuscript [8]. Another study in top general medicine journals also substantiates these findings, claiming a lack of improvement in authors providing the necessary evidence for conducting an RCT [14].
In 2014, a study concluded that if researchers had evaluated systematic reviews for their respective research question, many of the studies would not have been conducted and a significant number of adverse outcomes could have been avoided [2]. To mitigate this issue, we recommend when submitting for funding, trialists be required to conduct a thorough literature search including systematic reviews and meta-analyses. For example, the National Institute for Health Research in the United Kingdom requires all submissions for grant money to detail the existing evidence for their current project [15].

Taking it a step further, when submitting for publication, journals should consider requiring proof that a formal literature review was completed prior to conducting the trial. We anticipate that this action step would lead to fewer studies being conducted where evidence for the proposed intervention already exists, as well as eliminating trials that would add little value to the current literature. Fewer unnecessary studies would then minimize the risk and potential harm incurred by patients enrolled in RCTs. Eliminating research waste is not only a researcher's scientific responsibility, but also their ethical responsibility. It raises ethical questions to conduct a clinical 
Table 2 Analysis of trial characteristics and systematic review citations per journal and sections $-n(\%)$.

\begin{tabular}{|c|c|c|c|c|c|c|}
\hline Characteristics & $\mathrm{AJO}$ & JAMA & $\mathrm{O}$ & IOVS & Retina & Total \\
\hline Total studies ${ }^{\mathrm{a}}$ & $46(30.3)$ & $15(9.9)$ & $60(39.5)$ & $19(12.5)$ & $12(7.9)$ & 152 \\
\hline Total SRs cited ${ }^{\mathrm{b}}$ & 35 & 14 & 37 & 11 & 5 & 102 \\
\hline Introduction & 16 & 7 & 23 & 8 & 3 & 57 \\
\hline Methods & 0 & 0 & 0 & 0 & 0 & 0 \\
\hline Discussion & 19 & 7 & 14 & 3 & 2 & 45 \\
\hline $\begin{array}{l}\text { Trials that cited SRs verbatim as } \\
\text { justification for } \mathrm{RCT}^{\mathrm{b}}\end{array}$ & 4 & 1 & 7 & 2 & 0 & 14 \\
\hline Introduction & 3 & 0 & 6 & 2 & 0 & 11 \\
\hline Methods & 0 & 0 & 0 & 0 & 0 & 0 \\
\hline Discussion & 1 & 1 & 1 & 0 & 0 & 3 \\
\hline $\begin{array}{l}\text { Trials that cited SRs as inferred } \\
\text { justification for } \mathrm{RCT}^{\mathrm{b}}\end{array}$ & 12 & 5 & 6 & 2 & 3 & 28 \\
\hline Introduction & 6 & 4 & 4 & 2 & 3 & 19 \\
\hline Methods & 0 & 0 & 0 & 0 & 0 & 0 \\
\hline Discussion & 6 & 1 & 2 & 0 & 0 & 9 \\
\hline $\begin{array}{l}\text { Trials that cited SRs, but not used as } \\
\text { justification for } \mathrm{RCT}^{\mathrm{b}}\end{array}$ & 11 & 4 & 14 & 3 & 2 & 34 \\
\hline Introduction & 3 & 1 & 7 & 0 & 0 & 11 \\
\hline Methods & 0 & 0 & 0 & 0 & 0 & 0 \\
\hline Discussion & 8 & 3 & 7 & 3 & 2 & 23 \\
\hline $\begin{array}{l}\text { Trials that cited SR as justification for } \\
\text { conducting the trial }^{\mathrm{c}}\end{array}$ & $11(26.1)$ & $4(26.7)$ & $12(20.0)$ & $4(21.1)$ & $3(25.0)$ & $34(22.4)^{\mathrm{a}}$ \\
\hline \multicolumn{7}{|c|}{$\begin{array}{l}S R \text { systematic review, } R C T \text { randomized control trials, AJO American Journal of Ophthalmology, JAMA } \\
\text { JAMA Ophthalmology, } O \text { Ophthalmology, IOVS Investigative Ophthalmology and Vision Science }\end{array}$} \\
\hline \multicolumn{7}{|l|}{ aPercentage out of 152 total trials } \\
\hline${ }^{\mathrm{b}}$ Some trials contained verbatim/inferrec & he introdu & ction and c & discussio & and theref & were cou & unted twice \\
\hline
\end{tabular}

trial without proper justification through thorough evaluation of the literature, i.e., systematic reviews. As this unjustified trial may subject participants to unwarranted risks and complications [16].

We feel our methodology is robust and ensures reliability through a blinded and duplicated extraction method. However, we acknowledge a few limitations. First, our findings are limited to the top five ophthalmology journals and may not be generalizable across the entirety of ophthalmology literature. Second, there is a subjective component to determining when a systematic review is cited as verbatim, inferred, or not justifying the RCT that may affect the results. Finally, we understand that reproducibility within science is important and corroborating a result is paramount for reliable data; thus, replicative studies should be labeled as such and not considered wasted research.

Our findings suggest oversight on the part of some ophthalmology researchers in the evaluation of systematic reviews prior to designing an RCT. We believe that placing a higher priority on justifying RCTs with systematic reviews would go a long way to minimizing research waste within ophthalmology and optometry.

\section{Summary}

\section{What was known before}

- Research waste has become far too common, as one study suggests as much as $85 \%$ of research could be considered wasteful. One study found that over $50 \%$ of research studies analyzed did not consult a systematic review before designing the study. A major influencer of research waste within ophthalmology is a lack of standardization in RCT primary outcomes. For example, one study found extensive diversity within primary outcomes in registered uveitis trials.

\section{What this study adds}

- Less than one-quarter of phase III RCTs cited systematic reviews as justification for conducting the RCT. This aligns with a similar study in anesthesiology. To mitigate this issue, we recommend when submitting for funding, trialists be required to conduct a thorough literature search including systematic reviews and meta-analyses. 
Table 3 Characteristics of the systematic reviews used to justify (verbatim or inferred) RCTs.

\begin{tabular}{|c|c|c|}
\hline Systematic review & Included studies & Total participants \\
\hline $\begin{array}{l}\text { Efficacy and safety of intravitreal therapy in macular edema due to branch and } \\
\text { central retinal vein occlusion: a systematic review }\end{array}$ & 11 & 3434 \\
\hline $\begin{array}{l}\text { Rebamipide helps defend against nonsteroidal anti-inflammatory drugs induced } \\
\text { gastroenteropathy: a systematic review and meta-analysis }\end{array}$ & 15 & 939 \\
\hline $\begin{array}{l}\text { The comparative efficacy and safety of topical nonsteroidal anti-inflammatory drugs } \\
\text { for the treatment of anterior chamber inflammation after cataract surgery: a } \\
\text { systematic review and network meta-analysis }\end{array}$ & 19 & 7234 \\
\hline $\begin{array}{l}\text { Corneal cross linking and infectious keratitis: a systematic review with a meta- } \\
\text { analysis of reported cases }\end{array}$ & 12 & 104 (eyes) \\
\hline Medical versus surgical interventions for open angle glaucoma. & 4 & 888 \\
\hline $\begin{array}{l}\text { Uveitis-a rare disease often associated with systemic diseases and infections-a } \\
\text { systematic review of } 2619 \text { patients }\end{array}$ & $\begin{array}{l}\text { Not reported } \\
\text { within SR }\end{array}$ & 2619 \\
\hline How effective is low vision service provision? A systematic review & 7 & 906 \\
\hline $\begin{array}{l}\text { Global prevalence of age-related macular degeneration and disease burden } \\
\text { projection for } 2020 \text { and 2040: a systematic review and meta-analysis }\end{array}$ & 39 & 129,664 \\
\hline Medical interventions for fungal keratitis & 12 & 568 \\
\hline $\begin{array}{l}\text { Effect of graft thickness on visual acuity after descemet stripping endothelial } \\
\text { keratoplasty: a systematic review and meta-analysis }\end{array}$ & 31 & 2214 \\
\hline Laser peripheral iridoplasty for angle-closure & 1 & 158 \\
\hline Interventions for branch retinal vein occlusion: an evidence-based systematic review & 12 & 1026 \\
\hline $\begin{array}{l}\text { Economic and humanistic burden of dry eye disease in Europe, North America, and } \\
\text { Asia: a systematic literature review }\end{array}$ & 22 & 36,537 \\
\hline Interventions for preventing posterior capsule opacification & 66 & 8079 \\
\hline $\begin{array}{l}\text { Systemic safety of prolonged monthly antivascular endothelial growth factor } \\
\text { therapy for diabetic macular edema: a systematic review and meta-analysis }\end{array}$ & 4 & 1342 \\
\hline Epidemiology of diabetic retinopathy and macular edema: a systematic review & 359 & $\begin{array}{l}\text { Not reported } \\
\text { within SR }\end{array}$ \\
\hline Laser photocoagulation for neovascular age-related macular degeneration & 15 & 2064 \\
\hline $\begin{array}{l}\text { Objective assessment of compliance and persistence among patients treated for } \\
\text { glaucoma and ocular hypertension: a systematic review }\end{array}$ & 58 & 665,750 \\
\hline Interventions for improving adherence to ocular hypotensive therapy & 16 & 1565 \\
\hline $\begin{array}{l}\text { Efficacy, safety, predictability, aberrations and corneal biomechanical parameters } \\
\text { after SMILE and FLEx: meta-analysis }\end{array}$ & 7 & 361 (eyes) \\
\hline Clinical outcomes of SMILE and FS-LASIK used to treat myopia: meta-analysis & 11 & 1101 (eyes) \\
\hline $\begin{array}{l}\text { A systematic review and meta-analysis of clinical outcomes of vitrectomy with or } \\
\text { without intravitreal bevacizumab pretreatment for severe diabetic retinopathy }\end{array}$ & 6 & 281 \\
\hline $\begin{array}{l}\text { Antivascular endothelial growth factor for prevention of postoperative vitreous } \\
\text { cavity hemorrhage after vitrectomy for proliferative diabetic retinopathy }\end{array}$ & 12 & 654 \\
\hline $\begin{array}{l}\text { Vitrectomy with or without preoperative intravitreal bevacizumab for proliferative } \\
\text { diabetic retinopathy: a meta-analysis of randomized controlled trials }\end{array}$ & 8 & 394 \\
\hline Clinical trials in allergic conjunctivitis: a systematic review & 362 & $\begin{array}{l}\text { Not reported } \\
\text { within SR }\end{array}$ \\
\hline $\begin{array}{l}\text { Systematic review of randomized clinical trials on topical ciclosporin A for the } \\
\text { treatment of dry eye disease }\end{array}$ & 18 & 2337 \\
\hline $\begin{array}{l}\text { Efficacy of polyunsaturated fatty acids for dry eye syndrome: a meta-analysis of } \\
\text { randomized controlled trials }\end{array}$ & 9 & 716 \\
\hline $\begin{array}{l}\text { Efficacy of Mitomycin C in endoscopic dacryocystorhinostomy: a systematic } \\
\text { review and meta-analysis }\end{array}$ & 11 & 574 (eyes) \\
\hline $\begin{array}{l}\text { Systematic review and meta-analysis on outcomes for endoscopic versus external } \\
\text { dacryocystorhinostomy }\end{array}$ & 19 & 2026 \\
\hline \multirow[t]{2}{*}{ Healthcare via cell phones: a systematic review } & 25 & 38,060 \\
\hline & 53 & 3447 \\
\hline
\end{tabular}


Table 3 (continued)

\begin{tabular}{|c|c|c|}
\hline Systematic review & Included studies & Total participants \\
\hline \multicolumn{3}{|l|}{$\begin{array}{l}\text { The natural history and prognosis of neovascular age-related macular degeneration a } \\
\text { systematic review of the literature and meta-analysis }\end{array}$} \\
\hline $\begin{array}{l}\text { The prevalence of age-related macular degeneration in Asians: a systematic review } \\
\text { and meta-analysis }\end{array}$ & 9 & Unavailable \\
\hline $\begin{array}{l}\text { Characteristics of effective collaborative care for treatment of depression: a } \\
\text { systematic review and meta-regression of } 74 \text { randomized controlled trials }\end{array}$ & 74 & 21,345 \\
\hline $\begin{array}{l}\text { Toric intraocular lenses in the correction of astigmatism during cataract surgery: a } \\
\text { systematic review and meta-analysis }\end{array}$ & 13 & 1638 \\
\hline $\begin{array}{l}\text { Epidemiology and disease burden of pathologic myopia and myopic choroidal } \\
\text { neovascularization: an evidence-based systematic review }\end{array}$ & 38 & a \\
\hline $\begin{array}{l}\text { Efficacy and tolerability of prostaglandin analogs: a meta-analysis of randomized } \\
\text { controlled clinical trials }\end{array}$ & 8 & 1610 \\
\hline $\begin{array}{l}\text { Meta-analysis of randomized controlled trials comparing latanoprost with timolol in } \\
\text { the treatment of patients with open angle glaucoma or ocular hypertension }\end{array}$ & 11 & 1256 \\
\hline $\begin{array}{l}\text { Systemic safety of bevacizumab versus ranibizumab for neovascular age-related } \\
\text { macular degeneration }\end{array}$ & 9 & 3665 \\
\hline $\begin{array}{l}\text { Systemic safety of prolonged monthly antivascular endothelial growth factor } \\
\text { therapy for diabetic macular edema A systematic review and meta-analysis }\end{array}$ & 4 & 1328 \\
\hline $\begin{array}{l}\text { Combined intravitreal anti-VEGF and photodynamic therapy versus photodynamic } \\
\text { monotherapy for polypoidal choroidal vasculopathy: a systematic review and meta- } \\
\text { analysis of comparative studies }\end{array}$ & 11 & 543 \\
\hline $\begin{array}{l}\text { Ranibizumab alone or in combination with photodynamic therapy versus } \\
\text { photodynamic therapy for polypoidal choroidal vasculopathy: a systematic review } \\
\text { and meta-analysis }\end{array}$ & 9 & 465 \\
\hline Interventions for central serous chorioretinopathy: a network meta-analysis & 25 & 1098 \\
\hline
\end{tabular}

${ }^{a}$ Population based systematic review

We anticipate this action step would lead to fewer studies being conducted where evidence for the proposed intervention already exists, as well as eliminating trials that would add little value to the current literature. Fewer unnecessary studies would then minimize the risk and potential harm incurred by patients enrolled in RCTs.

\section{Compliance with ethical standards}

Conflict of interest The authors declare that they have no conflict of interest.

Publisher's note Springer Nature remains neutral with regard to jurisdictional claims in published maps and institutional affiliations.

\section{References}

1. The U.S. National Library of Medicine. Citations added to MEDLINE $^{\circledR}$ by fiscal year. 2007. https://www.nlm.nih.gov/bsd/ stats/cit_added.html. Accessed 21 Mar 2019.

2. Chalmers I, Bracken MB, Djulbegovic B, Garattini S, Grant J, Gülmezoglu AM, et al. How to increase value and reduce waste when research priorities are set. Lancet. 2014;383:156-65.
3. Conte ML, Liu J, Schnell S, Omary MB. Globalization and changing trends of biomedical research output. JCI Insight. 2017;2. https://doi.org/10.1172/jci.insight.95206.

4. University of Rochester Medical Center. Study: era of rapid growth in biomedical research over. 2010. https://www.urmc. rochester.edu/news/story/2736/study-era-of-rapid-growth-inbiomedical-research-over.aspx. Accessed 21 Mar 2019.

5. Chalmers I, Glasziou P. Avoidable waste in the production and reporting of research evidence. Obstet Gynecol. 2009;114:1341-5. https://doi.org/10.1097/aog.0b013e3181c3020d.

6. Chalmers I, Bracken MB, Djulbegovic B, Garattini S, Grant J, Metin Gülmezoglu A, et al. How to increase value and reduce waste when research priorities are set. Lancet. 2014;383:156-65. https://doi.org/10.1016/s0140-6736(13)62229-1.

7. Glasziou P, Chalmers I, Rawlins M, McCulloch P. When are randomised trials unnecessary? Picking signal from noise. BMJ. 2007;334:349-51. https://doi.org/10.1136/bmj.39070.527986.68.

8. Engelking A, Cavar M, Puljak L. The use of systematic reviews to justify anaesthesiology trials: a meta-epidemiological study. Eur J Pain. 2018;22:1844-9. https://doi.org/10.1002/ejp.1280.

9. American Academy of Ophthalmology. About compendiumAmerican academy of ophthalmology. https://www.aao.org/aboutcompendium. Accessed 28 June 2019.

10. Evans JR, Lawrenson JG. Antioxidant vitamin and mineral supplements for preventing age-related macular degeneration. Cochrane Database Syst Rev. 2012;6:CD000253.

11. Rosenthal R, Bucher HC, Dwan K. The use of systematic reviews when designing and reporting surgical trials. Ann Surg. 2017;265: e35-6. https://doi.org/10.1097/sla.0000000000001092. 
12. Denniston AK, Holland GN, Kidess A, Nussenblatt RB, Okada AA, Rosenbaum JT, et al. Heterogeneity of primary outcome measures used in clinical trials of treatments for intermediate, posterior, and panuveitis. Orphanet J Rare Dis. 2015;10:97.

13. Ismail R, Azuara-Blanco A, Ramsay CR. Consensus on outcome measures for glaucoma effectiveness trials: results from a delphi and nominal group technique approaches:: Core Outcome Measures in Effectiveness Trials Initiative (COMET). 2016. http://www.comet-initiative.org/studies/details/241. Accessed 11 Oct 2019.
14. Clarke M, Hopewell S, Chalmers I. Clinical trials should begin and end with systematic reviews of relevant evidence: 12 years and waiting. Lancet. 2010;376:20-1.

15. Mahtani K. Systematic reviews to reduce research waste. BMJ EBM Spotlight. 2017. https://blogs.bmj.com/bmjebmspotlight/ 2017/09/26/using-systematic-reviews-to-reduce-research-waste-w ho-really-cares/. Accessed 21 Mar 2019.

16. De Meulemeester J, Fedyk M, Jurkovic L, Reaume M, Dowlatshahi D, Stotts G, et al. Many randomized clinical trials may not be justified: a cross-sectional analysis of the ethics and science of randomized clinical trials. J Clin Epidemiol. 2018;97:20-5. 